\title{
Prediction of Surface Roughness from Cutting Tool Vibrations in Hard Turning of AISI D2 Steel of Different Hardness with Conventional and Wiper Geometry CBN Inserts
}

Sarnobat SS* and Raval HK

Department of Mechanical Engineering, Research and Development Division, Sardar Vallabhbhai National Institute of Technology, Surat, Gujarat, India

\begin{abstract}
The quality of machined surface is of vital significance due to its bearing of the in-service functionality of the component. In-service functionality of the machined parts like, tribological performance, fatigue life of the component etc.; are greatly dependent on the surface profile characteristic and the surface roughness generated after machining. However, the quality of surface is reliant on complexities of the numerous process parameters. The mechanics of metal cutting necessarily results into the dynamic instability of the process consequentially ensuing into cutting tool vibrations. Previous research indicates an association between the cutting tool vibrations and surface roughness. In this study the cutting tool vibrations in tangential and axial direction have been integrated with the input parameters; cutting speed, feed rate, depth of cut, work material hardness and tool edge geometry to develop prediction models for surface roughness from the experimentally obtained data by using Regression Analysis and artificial Neural Network methodologies. The results of the regression models and neural networks model are compared. A good agreement between the experimental and predicted values for both the models is seen, however neural networks approach outclasses regression analysis by a reasonable margin. Further it is also noted that the quality of surface is markedly influenced by the tool edge geometry and feed rate.
\end{abstract}

Keywords: AIS D2 steel; Cutting tool vibrations; Surface roughness; Regression analysis; Artificial Neural Networks

\section{Nomenclature}

$\mathrm{V}_{\mathrm{c}}$ : Cutting speed $(\mathrm{m} / \mathrm{min}) ; \mathrm{f}$ : feed rate $(\mathrm{mm} / \mathrm{rev}) ;$ ap: Depth of cut $(\mathrm{mm}) ; \mathrm{H}:$ Work material hardness (HRc); EG: Tool edge geometry; $\mathrm{Vx}$ : Axial acceleration of cutting tool vibrations $\left(\mathrm{mm} / \mathrm{s}^{2}\right) ; \mathrm{V}_{z}$ : Tangential acceleration of cutting tool vibrations $\left(\mathrm{mm} / \mathrm{s}^{2}\right) ; R_{a}$ : Surface roughness $(\mu \mathrm{m})$; ANOVA: Analysis of Variance; ANN: Artificial Neural Networks; MSE: Mean Squared Error; MAPE: Mean Absolute Percent Error; LH: Light Honed; W: Wiper

\section{Introduction}

In the very recent hard turning has evolved as an efficient and cost effective alternative to grinding for turning of ferrous components, hardened above 45 HRc. Broadly hard machining finds a wide application in manufacturing of bearings, tools, dies etc. The process mostly preferred for semi finishing and finishing operations requires lesser setup times, offers flexibility and thereby increases the productivity. A comprehensive report of the various aspects in hard turning has been presented by Gaurav Bartarya [1]. The advances in the cutting tool technology has made of hard turning feasible with ceramic and CBN tools finding a wide application. However; proper tool edge preparation is an important prerequisite for achieving desired performance in hard turning [2]. Demand of ever increasing high quality standards of the finished product is a pressing challenge the manufactures are facing in globalized industrial scenario. Achieving good surface finish along with precise control of dimensional \& geometric tolerances of the finished component is one of the vital criterions of product quality. The surface roughness of the finished component is closely related to the functional performance of the component during its service life. Several functional aspects like wear behavior, corrosion resistance and fatigue life greatly depend on the surface roughness. Hence the importance of achieving close control over surface roughness is of vital importance. However the surface roughness of the finished component depends on numerous factors. $R a \approx \frac{f 2}{32 r}$ is the most commonly and widely accepted model for estimation of surface roughness is. This equation depicts the relationship between surface roughness, feed rate and nose radius of the tool. However the surface roughness is affected by numerable other factors as machining tool conditions, cutting tool vibrations, properties of the work material and the dynamics of machining process [3]. This creates a nonlinear and complex dependence of surface roughness on all these factors which the conventional model $R a \approx \frac{f 2}{32 r}$ doesn't take into account. Therefore prediction of surface roughness by accommodating maximum possible factors has been of great interest for several researchers. Different approaches ranging for experimentations to artificial intelligence based approach have been applied by various researchers for accurate prediction of surface roughness. Vibrations in metal cutting are unavoidable but necessarily have a detrimental effect on the surface quality of the finished part. The quality of surface is significantly related to the vibrations [4]. Therefore vibration analysis and measures to keep vibrations under control is the interest of the researchers and manufacturers. Several researchers have attempted to study and analyze the vibrations in a metal cutting

${ }^{*}$ Corresponding author: Sarnobat SS, Research Scholar, Department of Mechanical Engineering, Research and Development Division, Sardar Vallabhbhai National Institute of Technology, Surat, Gujarat, India, Tel: +9120 27653058; E-mail: sssarnobat@gmail.com

Received January 14, 2018; Accepted January 31, 2018; Published February 04,2018

Citation: Sarnobat SS, Raval HK (2018) Prediction of Surface Roughness from Cutting Tool Vibrations in Hard Turning of AISI D2 Steel of Different Hardness with Conventional and Wiper Geometry CBN Inserts. J Appl Mech Eng 7: 300 doi:10.4172/2168-9873.1000300

Copyright: (C) 2018 Sarnobat SS, et al. This is an open-access article distributed under the terms of the Creative Commons Attribution License, which permits unrestricted use, distribution, and reproduction in any medium, provided the original author and source are credited. 
operation. Arizmendi [5] has reported the deteriorating influence of the cutting tool vibrations on the surface quality. The correlation of the dynamic force with the amplitude and natural frequency cutting tool vibration has been reported by Thomas [6] the authors have further noted the effect of the vibrations on the surface roughness due to tool overhang. The effect of the various machining system components on the too-work vibrations has been reported by Junyun Chenand [7]. Modeling and analysis of surface roughness by including tangential and radial acceleration of vibrations along with process parameters is suggested by Hessainia [8] while Upadhyay [9] incorporated the vibration signals in all the three axes for development of regression and neural networks models. Measurement and analysis of the influence of the tool tip vibration frequency on surface quality has been reported by Wang [10]. Investigations of the influence of the tool angles on the vibrations have been carried out by Subramanian [11] and the authors suggested a converse relation between the vibrations and tool angles. Prediction of surface quality by amalgamation of features mined from vibration signals along process and tool parameters has been proposed by Salgado [12]. Modeling of surface quality by blending the tangential vibrations with process parameters by using fuzzy-net approach has been carried out by Kirby [13]. Surface roughness prediction system based on accelerometers to incorporate the vibrations of the cutting tool has been illustrated by Ahang [14]. Thus from the past research works the prominence of the cutting tool vibrations on the resultant quality of the surface is evident and hence the present study focusses on finding a correlation between the surface roughness and cutting tool vibrations in consort with the process parameters in turning of AISI D2 steel hardened to different hardness levels by CBN inserts of different edge geometries. An empirical modeling approach based on regression analysis is proposed to model the experimental data and arrive at an relation between the tool vibrations and the quality of surface. Further neural networks based modeling has been proposed and the efficacy of the ANN models is compared with the regression models.

\section{Experimentation}

\section{Equipment, material, cutting tools and measurement set up}

The work material used for experimentation is AISI D2 steel which is also known as cold work tool steel richer in carbon and chromium content along with molybdenum and vanadium added as alloying elements in smaller quantities. This material is widely used for manufacturing of dies and punches due to its high resistance to wear, excellent toughness and dimensional stability. In the current study round bars of $32 \mathrm{~mm}$ diameter and $55 \mathrm{~mm}$ length were hardened and tempered to achieve hardness as $50 \pm 2,55 \pm 2$ and $60 \pm 2 \mathrm{HRc}$. Table 1 below indicates the chemical composition of AISI D2 steel work material (Figures 1 and 2).

In the hard turning process the cutting tool edge geometry has a significant influence on the surface quality, dimension and form stability, cutting forces etc. on one hand and tool wear on the other [1]. The specimen have been turned on a CNCDX-200 turning centre in dry turning condition for a $15 \mathrm{~mm}$ length of cut with CBN tools of Tungaloy make having tool specifications as below in Figure 3 and Tungaloy tool holder DCLNL $25 \times 25 \mathrm{M} 12$ left handed tool holder was used to mount the $\mathrm{CBN}$ inserts with specifications as rake angle of $-6^{\circ}$, clearance angle of $6^{\circ}$, inclination angle of $-6^{\circ}$ and approach angle of $95^{\circ}$.

\begin{tabular}{|c|c|c|c|c|c|c|c|}
\hline $\mathbf{C}$ & $\mathbf{S i}$ & $\mathbf{M n}$ & $\mathbf{C r}$ & $\mathbf{M o}$ & $\mathbf{V}$ & $\mathbf{P}$ & $\mathbf{S}$ \\
\hline $1.58 \%$ & $0.29 \%$ & $0.37 \%$ & $11.65 \%$ & $0.82 \%$ & $0.94 \%$ & $0.023 \%$ & $0.008 \%$ \\
\hline \multicolumn{10}{c}{ Table 1: Chemical composition of work material. }
\end{tabular}
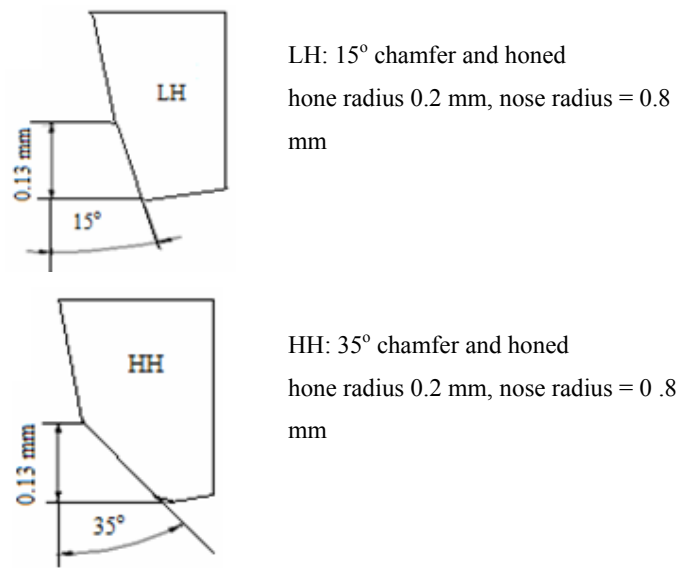

HH: $35^{\circ}$ chamfer and honed

hone radius $0.2 \mathrm{~mm}$, nose radius $=0.8$ $\mathrm{mm}$

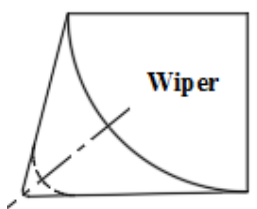

Wiper geometry

nose radius $=0.8 \mathrm{~mm}$

Figure 1: Tool edge geometries.
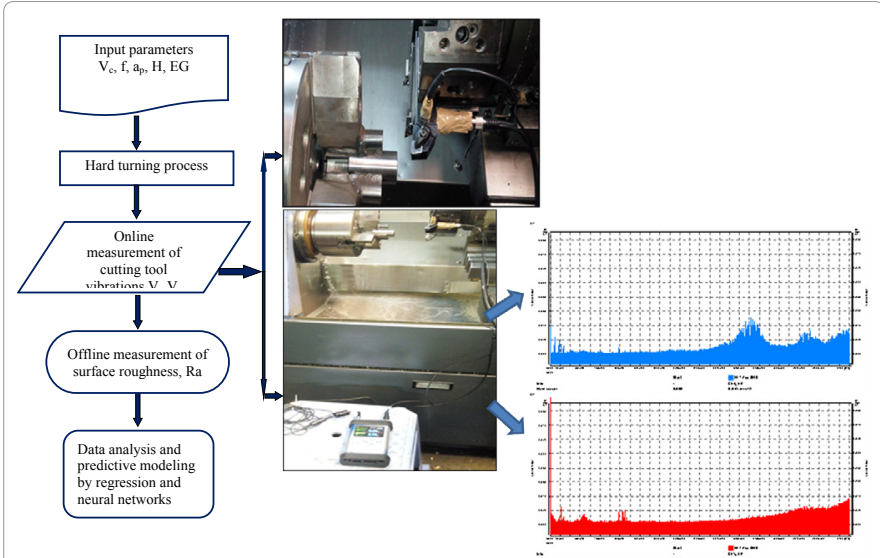

Figure 2: Schematic of experimental methodology.

The tangential and axial accelerations of the cutting tool vibrations are acquired online with the aid of two uniaxial accelerometers (7105A and SV80), mounted on the tool holder. The RMS (root mean square) value of the acceleration is recorded with a data acquisition system consisted of 4-channel sound and vibration analyser SVAN 958A. The recorded data has been further downloaded in graphical and text- format by using Svan PC++ software. The surface roughness is measured offline by using Mitutoyo 178-602 surface roughness tester at three locations and an average is taken. Figure 2 vividly portrays the experimental methodology.

\section{Experimental plan}

The experiments were designed by using Taguchi's design with $\mathrm{L}$ ${ }_{27}$ orthogonal array. The factors and their levels are specified in Table 2 which are finalized after extensive literature review and by reference to manufacturer's catalogue.

Twenty seven experiments are being conducted along with replicates, therefore in total 54 experiments are being conducted. 
Citation: Sarnobat SS, Raval HK (2018) Prediction of Surface Roughness from Cutting Tool Vibrations in Hard Turning of AISI D2 Steel of Different Hardness with Conventional and Wiper Geometry CBN Inserts. J Appl Mech Eng 7: 300. doi:10.4172/2168-9873.1000300

Page 3 of 7

\section{Results and Discussion}

The work of Kirby [13] suggests that inclusion of the vibrations signals into the prediction model increases the prediction accuracy. Therefore an attempt has been made to include the vibration signals i.e., tangential and axial accelerations into the prediction models so as to enable determination of the surface roughness. Multiple regression analysis and artificial neural networks approach have been applied for this. Based on the vibrations and surface roughness data acquired summarized in Table 3 and presented elsewhere by Sarnobat [15] the hierarchical regression model by stepwise addition of the terms with a $=0.1$ model has been developed and is shown in Table 4 .

\section{Variance analysis}

Based on the hierarchical regression model shown in Table 4, F-test and $\mathrm{p}$-test are employed to assess the significance of the input factor on the response A p-value $<0.05$ a statistical significance for the input on the response. The analysis of variance indicates that the regression model is significant at $\mathrm{p}$-value $=0.000$. The factors cutting speed, feed rate, depth of cut, hardness, edge geometry are significant as the $\mathrm{p}$ - value $<0.05$. The interaction of feed rate and axial acceleration vibration of cutting tool, feed rate and edge geometry, hardness of work material and edge

\begin{tabular}{|c|c|c|c|c|c|}
\hline Levels & \multicolumn{5}{|c|}{ Experimental factors } \\
$\begin{array}{c}\text { Cutting } \\
\text { speed } \\
\left(\mathbf{V}_{\mathbf{c}}\right)(\mathbf{m} / \mathbf{m i n})\end{array}$ & $\begin{array}{c}\text { Feed rate (f) } \\
(\mathbf{m m} / \mathbf{r e v})\end{array}$ & $\begin{array}{c}\text { Depth of cut } \\
\left(\mathbf{a}_{\mathbf{p}}\right)(\mathbf{m m})\end{array}$ & $\begin{array}{c}\text { Work material } \\
\text { Hardness H } \\
(\mathbf{H R c})\end{array}$ & $\begin{array}{c}\text { Edge } \\
\text { geometry } \\
(\mathbf{E G})\end{array}$ \\
\hline 1 & 60 & 0.05 & 0.10 & $50 \pm 2$ & $\begin{array}{c}\text { Light } \\
\text { Honed } \\
(\mathrm{LH})\end{array}$ \\
\hline 2 & 90 & 0.105 & 0.23 & $55 \pm 2$ & $\begin{array}{c}\text { Heavy } \\
\text { Honed } \\
(\mathrm{HH})\end{array}$ \\
\hline 3 & 120 & 0.16 & 0.35 & $60 \pm 2$ & Wiper (W) \\
\hline
\end{tabular}

Table 2: Factors setting and their levels.

\begin{tabular}{|c|l|l|l|l|l|}
\hline \multicolumn{2}{|c|}{ Tangential Acceleration } & \multicolumn{2}{c|}{ Axial Acceleration } & \multicolumn{2}{c|}{ Surface Roughness } \\
\hline \multicolumn{2}{|c|}{$\mathbf{V}_{\mathbf{z}}\left(\mathbf{m m} / \mathbf{s}^{2}\right)$} & \multicolumn{3}{c|}{$\mathbf{V}_{\mathbf{x}}\left(\mathbf{m m} / \mathbf{s}^{2}\right)$} & \multicolumn{2}{c|}{$\mathbf{R a}(\boldsymbol{\mu m})$} \\
\hline Max & \multicolumn{1}{|c|}{ Min } & Max & Min & Max & Min \\
\hline 9567 & 375 & 10673 & 480 & 0.92 & 12 \\
\hline
\end{tabular}

Table 3: Data range of measured output.

\begin{tabular}{|c|c|c|c|c|c|c|}
\hline Source & DF & Adj SS & Adj MS & F-value & P-value & $\begin{array}{c}\% \\
\text { Contribution }\end{array}$ \\
\hline Regression & 14 & 3.54969 & 0.253549 & 362.72 & 0.000 & -- \\
\hline$V_{c}$ & 1 & 0.01428 & 0.014275 & 20.42 & 0.000 & -- \\
\hline$f$ & 1 & 0.21718 & 0.217177 & 310.69 & 0.000 & 10.35 \\
\hline$a_{p}$ & 1 & 0.01694 & 0.016942 & 24.24 & 0.000 & -- \\
\hline $\mathrm{H}$ & 1 & 0.02951 & 0.029509 & 42.22 & 0.000 & -- \\
\hline EG & 2 & 1.00321 & 0.501605 & 717.59 & 0.000 & 47.83 \\
\hline$V_{x}$ & 1 & 0.02761 & 0.027609 & 39.50 & 0.000 & -- \\
\hline$V_{z}$ & 1 & 0.00368 & 0.003677 & 5.26 & 0.027 & -- \\
\hline$V c^{*} a_{p}$ & 1 & 0.04481 & 0.044815 & 64.11 & 0.000 & -- \\
\hline$f^{\star} V_{x}$ & 1 & 0.03760 & 0.037598 & 53.79 & 0.000 & -- \\
\hline$f^{\star} E G$ & 2 & 0.66112 & 0.330560 & 472.90 & 0.000 & 31.52 \\
\hline$H^{*} E G$ & 2 & 0.01412 & 0.007061 & 10.10 & 0.000 & -- \\
\hline Error & 39 & 0.02726 & -- & -- & -- & -- \\
\hline Total & 53 & 3.57695 & -- & -- & -- & -- \\
\hline \multicolumn{7}{|c|}{ Model Summary } \\
\hline $\mathbf{S}$ & R-Sq & R-Sq (adj) & $\begin{array}{c}\text { R-sq } \\
\text { (pred) }\end{array}$ & -- & -- & -- \\
\hline 0.0264389 & $99.24 \%$ & $98.96 \%$ & $98.59 \%$ & -- & -- & -- \\
\hline
\end{tabular}

Table 4: Regression model for surface roughness.

\begin{tabular}{|c|c|}
\hline $\begin{array}{c}\text { Edge } \\
\text { geometry }\end{array}$ & Regression Equation \\
\hline LH & $\begin{array}{c}-0.269-0.008285 * V_{c}+8.009 * f-3.142{ }^{*} a_{p}+0.01230 * H+ \\
0.000189 * V x-0.000014 * V z+0.03249 * V c{ }^{*} a_{p}-0.001161 * f^{*} V_{x}\end{array}$ \\
\hline $\mathrm{HH}$ & $\begin{array}{c}-0.2468-0.008285 * V_{c}+6.979 * f-3.142{ }^{*} a_{p}+0.01354 H+ \\
0.000189 * V_{x}-0.000014^{*} V_{z}+0.03249 * V_{c}{ }^{*} a_{p}-0.001161 * f^{*} V_{x}\end{array}$ \\
\hline W & $\begin{array}{l}0.4039-0.008285 * V_{c}+2.276 * f-3.142 * a_{p}+0.00508 H+ \\
0.000189 V_{x}-0.000014 V_{z}+0.03249 V_{c}^{*} a_{p}-0.001161 * f * V_{x}\end{array}$ \\
\hline
\end{tabular}

Table 5: Regression models for different tool edge geometries.

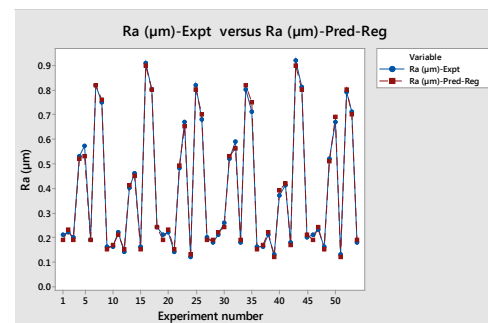

Figure 3: Comparison of experimental and regression modeling predictions for surface roughness.

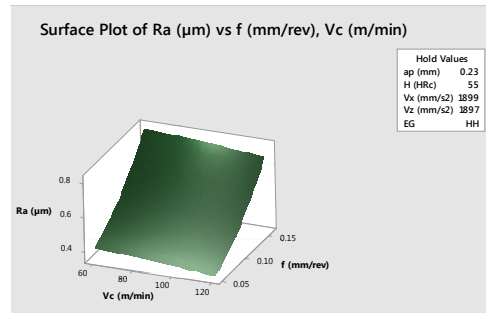

Figure 4: Surface plot of surface roughness versus feed rate and cutting speed.

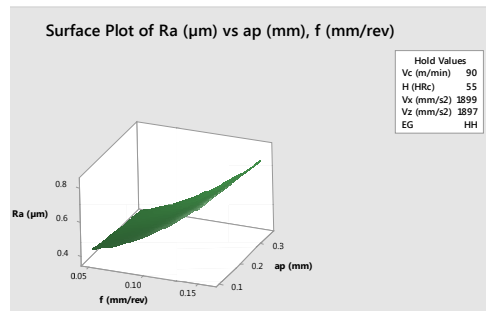

Figure 5: Surface plot of surface roughness versus depth of cut and feed rate.

geometry are also found to be significant. A contribution of $47.83 \%$ from the cutting tool edge geometry, $31.52 \%$ from the interaction of feed rate and cutting tool edge geometry and $10.35 \%$ from the feed rate is indicated. An R-sq of $99.86 \%$ shows that the model can be used to explain the variability and R-sq-pred of $98.30 \%$ indicated the model to be fit for prediction.

\section{Regression equations}

The regressions equations based on the regression model are formulated and are indicated as below in Table 5. The experimental and predicted values of surface roughness are plotted and shown in the Figure 3. It is seen that the experimental and predicted values are close with an overall mean absolute percent (MAPE) of 4.366

\section{Surface plots}

To graphically analyze the simultaneous effect of any two inputs on the response surface plots are utilized.

Figures 4-9 present the surface plots for average surface roughness 


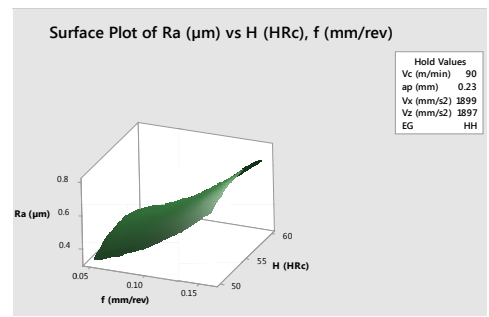

Figure 6: Surface plot of surface roughness versus work material hardness and feed rate.

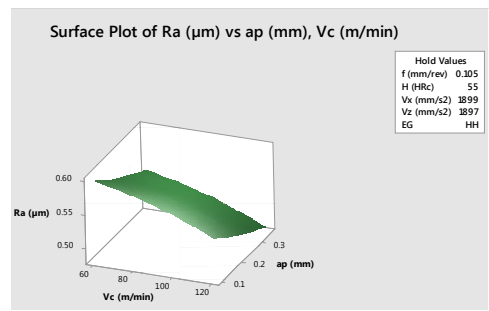

Figure 7: Surface plot of surface roughness versus depth of cut and cutting speed.

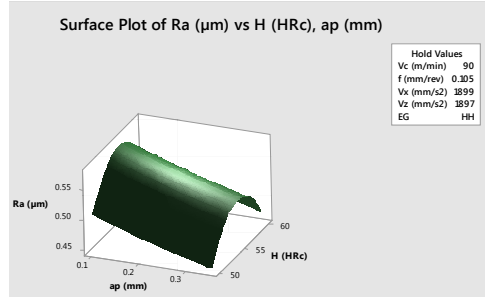

Figure 8: Surface plot of surface roughness versus work material hardness and depth of cut.

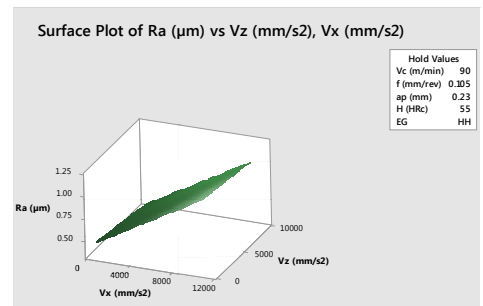

Figure 9: Surface plot of surface roughness versus axial acceleration and tangential acceleration.

versus the input parameters viz. cutting speed, feed rate, depth of cut, work material hardness, edge geometry and the cutting tool vibrations $\left(\mathrm{V}_{\mathrm{x}}\right.$ and $\left.\mathrm{V}_{\mathrm{z}}\right)$. It is seen from the surface plots that the surface roughness is most affected by feed rate. As seen from Figure 4 the surface roughness decreases with increase in the cutting speed, however increases considerably with increase in the feed rate. Similar observations are noted from Figure 5 which shows that higher surface roughness is obtained over the entire range of depth of cut when the feed rate is high and Figure 6 which depicts that the surface quality deteriorates as the feed rate increases over the entire hardness range. The increase in the feed rate causes increase in the resistant force acting on the tool tip thereby increasing the instability of the cutting process thereby damaging the quality of resulting surface [16].
From the surface plot of surface roughness versus cutting speed and depth of cut Figure 7 it quality of surface is seen to be better at higher cutting speed and higher depth of cut as presented in Figure 7.

Surface plot of quality of surface versus depth of cut and work material hardness as shown in Figure 8 depicts that the quality of surface deteriorates with increase in hardness up to $55 \mathrm{HRc}$ and further improves beyond 55HRc. As seen from Figure 9 the surface roughness is more affected by the axial vibration of the cutting tool than the vibrations in the tangential direction.

The surface roughness is considerably influenced by the tool edge geometry. The surface quality remarkably improves while machining with wiper geometry cutting tool as indicated from Figure 10 [17].

\section{Predictive modeling by neural networks}

Predictive modeling techniques are very common and being prevalently utilized by researcher's time and again so as to be able to predict the phenomenon for different sets of inputs without conducting the experiments again. This approach proves to be very efficient and effective in case of urgency and where resources are in dearth. Various statistical and soft computing techniques are in vogue and have been expansively applied. The accuracy of prediction of the soft computing techniques has also been found to be high in comparison to the other techniques statistical techniques and numerical modeling etc. [18-20]. The neural networks are inspired from the human nervous system, the ability of the human brain to learn and reproduce the learnt at similar decision making situations. In short, the neural networks mimic the human brain capabilities of learning and reproducing hence are also termed as Artificial neural networks (ANN). Commonly ANN models include equivalent computer models that are adaptive and have capabilities of solving complex problems. The neural networks model mimics the structure of a biological neuron. The following Figure 11 shows a comparison of a biological and artificial neuron. In artificial neural networks "nodes" resembling the biological "neurons are used which are connected to each other by a "link "that bear a resemblance to the "synapse, the "weights "assigned to each "link" is the "synaptic efficiency "and the output of the node is the "firing frequency. As shown in the Figure 12 the $\mathrm{x}_{\mathrm{n}}$ are the inputs which are multiplied by

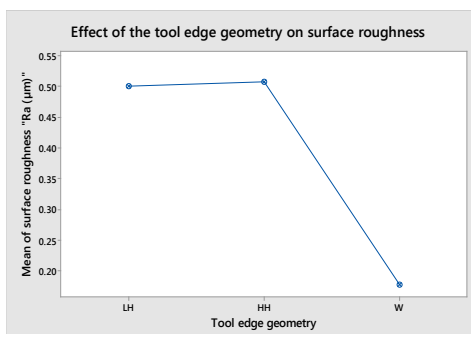

Figure 10: Effect of tool edge geometry on surface roughness.

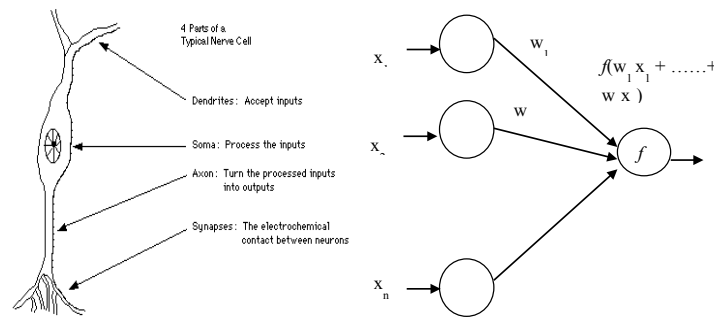

Figure 11: Biological neuron versus artificial neuron. 
a connection weight which are further summed up as; sum $=\mathrm{w}_{1} \mathrm{x}_{1}+$ $\ldots+\mathrm{w}_{\mathrm{n}} \mathrm{x}_{\mathrm{n}}$ and fed over the transfer function $f$ to generate a result and then output. The connection weights are updated while the network learns in such so as to minimize the mean square error amongst the real output and the preferred output in minimized. A layered feed forward neural network based on back propagation algorithm is utilized for this purpose. The artificial neurons are organized in layers viz. the input layer, the output layer and the hidden layer. A neural network can have more than one hidden layer. The signals from the neurons are forwarded through theses layers via the synapses and the output is calculated which is compared with the intended or targeted output to calculate the error. These errors are then back transmitted to revise the weights, this continues till the mean square error is minimised as stated earlier. The procedure of altering the weights is termed as learning or training of the network, begins with random assignment of the weights random weights, which are adjusted in due course till the error is minimized.

The equation suggests the net activation input for $i^{\text {th }}$ neurons by.

$$
n e t_{i}=\sum_{j=1}^{n} w_{i j} x_{j}
$$

Where, $w_{i j}=$ Weight of link connecting $i$ to $j$,

$o_{i}=\frac{1}{1+e_{i}^{\text {nnet }}}=$ output of the $i^{\text {th }}$ neuron for sigmoid transfer function

Where, $\mathrm{n}$ is the scaling factor, the revising of the weights is as state in equation 7.3

$$
w i_{j(n+1)}=w_{i j(n)}+\alpha \delta_{p i O p i}+\beta \Delta w i_{j(n)}
$$

Where,

$\mathrm{n}=$ learning step, $\alpha=$ the leaning rate, $\beta=$ the momentum constant.

$\delta_{p i}=$ error and given by:

- For output layer:

$\delta_{p k}=\left(d_{k \cdot p}-o_{k \cdot p}\right)\left(1-o_{k \cdot p}\right) ; k=1, \ldots . . K$

- For hidden layer:

$$
\delta_{p i}=o_{p j}\left(1-o_{p j}\right) \sum \delta_{p k} w_{k j} ; j=1, \ldots \ldots J
$$

The mean square error (MSE) due to all output and NP number of pattern is computed as:

$$
M S E=\frac{1}{N} \sum_{P=1}^{N} \sum_{k=1}^{K}\left(d_{k \cdot p}-o_{k \cdot p}\right)^{2}
$$

The training of the network is terminated if the MSE is less than specified or the number of epoch crosses the maximum specified limit.

The neural network model is developed to predict the measured outputs surface roughness using MATLAB R13a. The model is capable of predicting these outputs for the given inputs viz, cutting speed, feed rate, depth of cut, hardness and tool edge geometry, amplitude of tangential acceleration and amplitude of axial acceleration. The ANN model for prediction of the surface roughness is shown in Figure 12 below.

The experimental data acquired in measurement of surface roughness is used to develop the model. A total 54 number of data sets are therefore used. Out of these $80 \%$ data (44) are selected and has been used for testing and the $10 \%$ ( 5 data sets) for training and $10 \%$ (5 data sets) has been utilized. The widespread range of the inputs and the outputs along with the uncertainties of the process

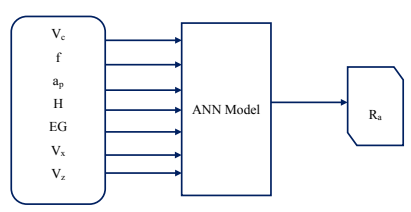

Figure 12: Schematic of ANN model.

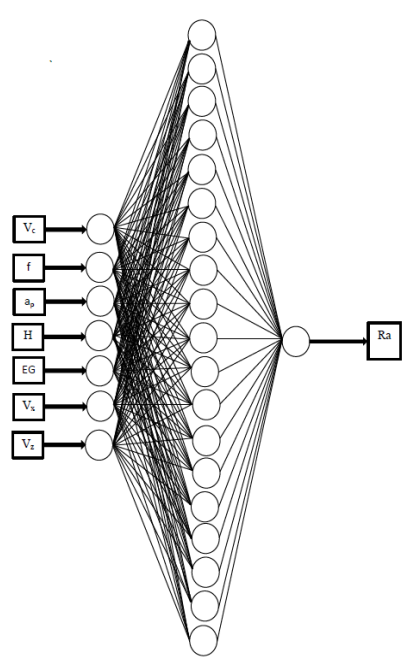

Figure 13: ANN architecture.

\begin{tabular}{|c|c|c|}
\hline Sr. No & Number of neurons in the hidden layer & MSE \\
\hline 1 & 10 & 0.00126 \\
\hline 2 & 15 & 0.000835 \\
\hline 3 & 19 & 0.000724 \\
\hline 4 & 25 & 0.000951 \\
\hline 5 & 32 & 0.00987 \\
\hline
\end{tabular}

Table 6: Number of neurons in hidden layer and MSE.

settings and the measurement technique greatly affect the prediction accuracy of the ANN model. The widespread range of the inputs and the outputs along with the uncertainties of the process settings and the measurement technique greatly affect the prediction accuracy of the ANN model. To mitigate this data is either normalized or transformed using logarithmic function. The data normalization and/or logarithmic transformation the range of the data sets significantly reduces thereby increasing the prediction accuracy of the model. Further data devoid of logarithmic transformation necessitates the ANN model to be trained many times or the complexity of the network increases in terms of the number of neurons in the hidden layer. The MSE reaches a minimum with less number of epochs when logarithmic transformation is used [20]. Hence the data sets are preprocessed to $\log _{10}$ scale before developing the network and the outputs are post processed by taking the antilog. The ANN architecture (Figure 13), developed is finalized after utilizing different training functions and by changing the number of neurons in the hidden layer as shown in Tables 6 and 7 respectively. The best network was obtained with 19 neurons in the hidden layer and Bayesian regularization training function;"trainlm" converging faster with minimum number of epochs of 4 than any other training function (Table 7) with a MSE of 0.000724 and is shown in Figure 14. An overall R (coefficient of correlation) of 0.99876 (Figure 15) is obtained representing good model adequacy. A decent conformity between the experimental and predicted values for training and testing 
Citation: Sarnobat SS, Raval HK (2018) Prediction of Surface Roughness from Cutting Tool Vibrations in Hard Turning of AISI D2 Steel of Different Hardness with Conventional and Wiper Geometry CBN Inserts. J Appl Mech Eng 7: 300. doi:10.4172/2168-9873.1000300

data is obtained for surface roughness and is indicated in the Figures 16 and 17 respectively.

The testing errors for the surface roughness prediction model are tabulated below in Table 8 and the average MAPE of 0.82 is achieved. The ANN predictions are noted to be in close agreement with the experimental results as specified in Table 8 and Figure 17.

The comparison of the regression models developed, and the neural networks models is compared by means of mean absolute percentage error for both the models as shown in Table 9 and Figures 18 and 19. It can be noted that the ANN model developed out performs regression modeling

\section{Conclusions}

1. Regression analysis and neural networks methodologies are

\begin{tabular}{|c|c|c|c|}
\hline Sr No & Training function & MSE & Epochs \\
\hline 1 & Train br & 0.0009752 & 9 \\
\hline 2 & Train Im & 0.000724 & 4 \\
\hline 3 & Traing dx & 0.0010957 & 12 \\
\hline 4 & Train $r p$ & 0.0007958 & 7 \\
\hline
\end{tabular}

Table 7: Different training functions and MSE.

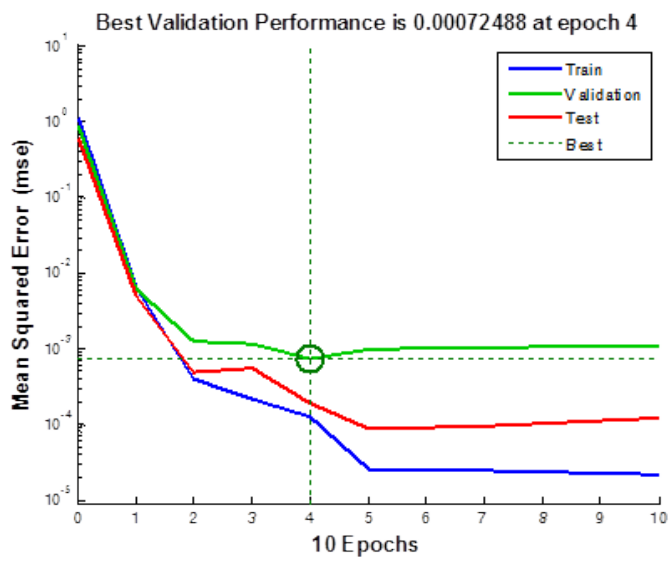

Figure 14: Performance for ANN model.
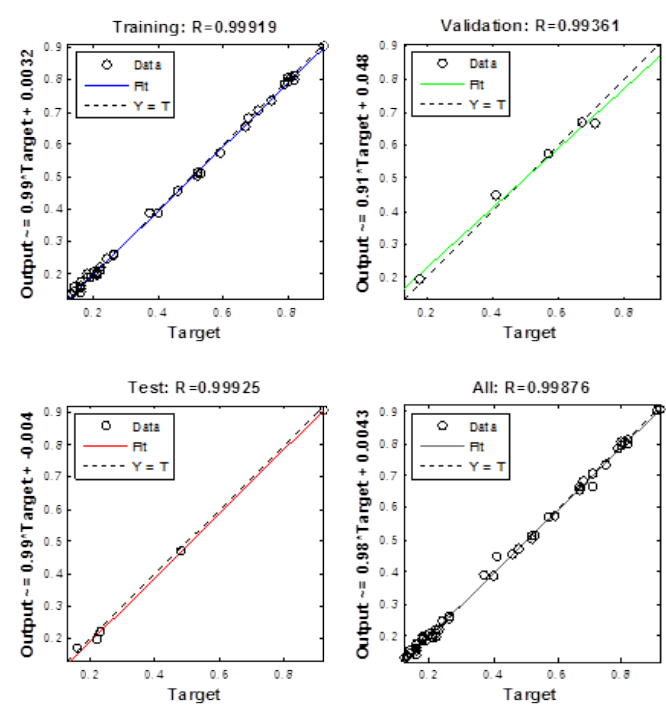

Figure 15: Regression for output versus target for surface roughness.

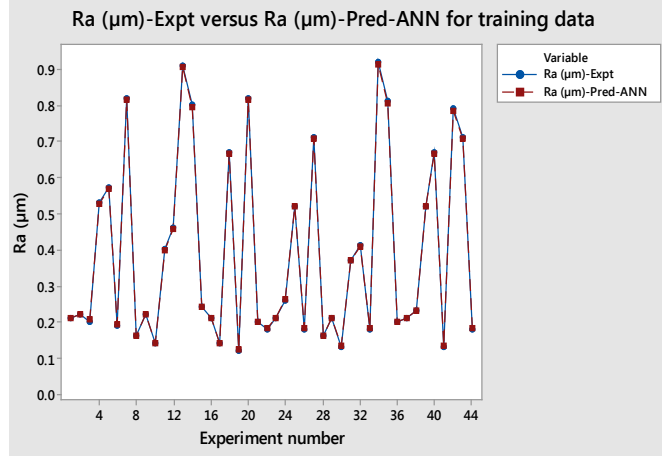

Figure 16: Experimental versus ANN predicted values of surface roughness for training data.

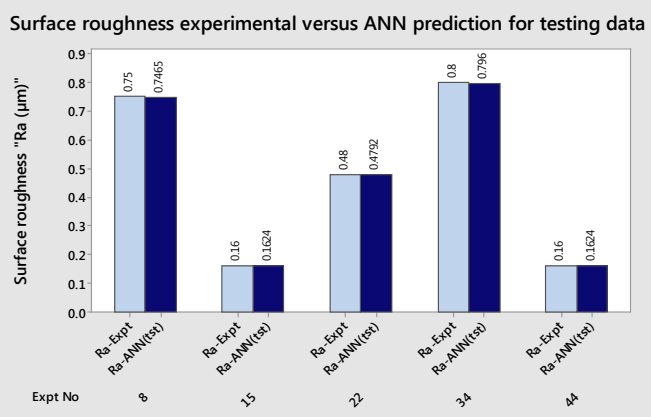

Figure 17: Experimental versus ANN predicted surface roughness for testing data.

\begin{tabular}{|c|c|c|c|c|c|}
\hline \multicolumn{7}{|c|}{ Average \% error } \\
\hline Expt No & Ra-Expt & Ra-ANN (tst) & Ra-Reg (tst) & Ra (Reg) & Ra ANN \\
\hline 8 & 0.75 & 0.7465 & 0.76 & 1.33 & 0.46 \\
\hline 15 & 0.16 & 0.1624 & 0.15 & 6.25 & 1.50 \\
\hline 22 & 0.48 & 0.4792 & 0.49 & 2.08 & 0.16 \\
\hline 34 & 0.8 & 0.796 & 0.82 & 2.5 & 0.50 \\
\hline 44 & 0.16 & 0.1624 & 0.15 & 6.25 & 1.50 \\
\hline-- & -- & -- & MAPE & 3.68 & 0.82 \\
\hline
\end{tabular}

Table 8: Experimental and predicted values of surface roughness for testing data.

\begin{tabular}{|c|c|}
\hline \multicolumn{2}{|c|}{ MAPE for Training data } \\
\hline Regression Analysis & ANN \\
\hline 4.622 & 0.6401 \\
\hline
\end{tabular}

Table 9: Mean absolute percent error for regression and ANN.

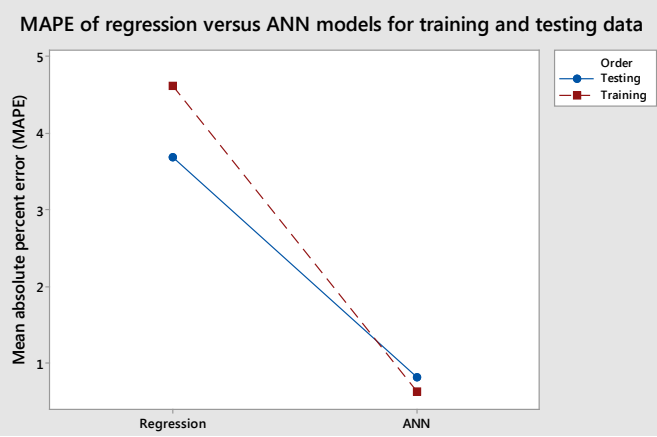

Figure 18: MAPE of regression versus ANN model for training and testing data. 


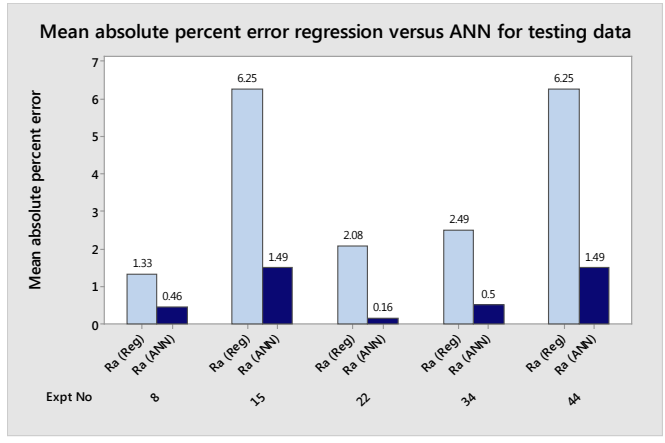

Figure 19: Absolute percent error regression versus ANN for testing data.

useful for prediction on surface roughness by integrating the cutting tool vibrations with other input parameters.

2. The results of variance analysis exhibits that the cutting tool edge geometry, interaction of feed rate and tool edge geometry and feed rate have the utmost effect on the surface roughness. The tool edge geometry (EG) with a contribution of $47.83 \%$, interaction of feed ratetool edge $(f \times E G)$ with a contribution of $31.52 \%$ and feed rate $(f)$ with a contribution of $10.35 \%$, influence the surface roughness.

3. Regression equations based on the hierarchical regression model have been deduced to correlate the surface roughness with the input parameters. A R-sq of 99.24 and R-sq.(pred) of 98.59 designate a good correlation of the response with the predictors.

4. Graphical analysis using surface plots for the regression model indicates that the surface roughness is significantly affected by feed rate after the tool edge. The wiper edge tool edge geometry resulted in the best surface quality in comparison to the conventionally honed tool edge geometries.

5. Both the regression and ANN models were found to be suitable for prediction of the surface roughness. Based on the mean absolute percent error the neural networks modelling provided an equitably exact prediction in comparison to regression analysis approach.

6. The methodology suggested in this study based on experimentation, statistical and neural network modeling can be effectively and efficiently utilized for surface roughness prediction in hard turning process.

\section{References}

1. Bartarya G, Choudhury SK (2012) State of the art in hard turning Int J Machine Tools \& Manufacture 53: 1-14.

2. Zel TO, Karpat Y, Figueira L, Paulo Davim J (2007) Modeling of surface finish and tool flank wear in turning of AISI D2 steel with ceramic wiper inserts. J Mater Process Technol 189: 192-198
3. Ratnam MM (2017) Factors affecting surface roughness in finish turning. Comprehensive 1: 1-25.

4. Bernardos PG, Vosniakos GC (2003) Predicting surface roughness in machining: a review. Int J Machine Tools and Manufact 43: 833-844.

5. Arizmendi M, Campa FJ, Fernandez J, Lopes de Lacalle LN, Gil A, et al. (2009) Model for surface topography prediction in peripheral milling considering tool vibration. CIRP Annals Manufact Technol 581: 93-96.

6. Thomas M, Beauchamp M, Youssef AY, Masounave J (1996) Effect of tool vibration on surface roughness during lathe dry turning process. Computers and Industrial Engineering 31: 637-644.

7. Chenand $\mathrm{J}$ (2015) A model for predicting surface roughness in single-point diamond turning. Measurement 69: 20-30.

8. Hessainia, Belbah A, Yallese M, Mabrouki T, Rigal JF (2013) On the prediction of surface roughness in the hard turning based on cutting parameters and tool vibrations. Measurements 46: 1671-1681.

9. Upadhyay V, Jain PK, Mehta NK (2013) In process prediction of surface roughness in turning of Ti-6al-4 AV alloy using cutting parameters and vibration signals. Measurements 46: 154-160.

10. Wang $\mathrm{H}$, To S, Chan CY (2013) Investigation on the influence of tool vibration on surface roughness and its representative measurement in ultra-precision diamond turning. Int J Machine tool \& Manufact 69: 20-29.

11. Subramanian M, Sakthivel M, Sooryaprakash K, Sudhakaran R (2013) Optimisation of end mill tool geometry parameters for Al7075-T6 machining operations based on vibration amplitude by response surface methodology. Measurement 46: 4005-4022.

2. Salgado DR, Alonso FJ, camber I, Marcelo A (2009) In-process surface roughness prediction system using cutting vibrations in turning. Int J Advanced Manufact Technol 43: 40-51.

13. Kirby ED, Chen JC (2007) Development of fuzzy net based surface roughness prediction system in turning operations, Computers \& Industrial Engineering 53: 30-42.

14. Kirby ED, Ahang Z, Chen JC (2004) Development of an accelerometer-based surface roughness prediction system in turning operations using multiple regression technique. J Ind Technol 20: 1-8.

15. Sarnobat SS (2017) Investigation of the performance of cutting tool edge geometry during CBN hard turning of AISI D2 steel with different hardness.

16. Chen CC, Ko-Ta C, Chih-Chung C, Yan-Ching L (2011) The use of D-optimal design for modeling and analyzing the vibration and surface roughness in the precision turning with diamond cutting tool. Int J Advanced Manufact Technol 54: $465-478$

17. Gaitonde VN, Karnik SR, Figueira L, Paulo Davim J (2011) Performance comparison of conventional and wiper ceramic inserts in hard turning through artificial neural network modeling. Int J Advanced Manufact Technol 52:101-114.

18. Mia M, Dhar NR (2016) Prediction of surface roughness in hard turning under high pressure coolant using Artificial Neural Network. Measurement 92: 464474.

19. Asiltürk I, Çunkas M (2011) Modeling and prediction of surface roughness in turning operations using artificial neural network and multiple regression method. Expert Systems with Applications 38: 5826-5832.

20. Channapattana SV, Pawar AA, Kamble PG (2017) Optimization of operating parameters of $\mathrm{DI}-\mathrm{Cl}$ engine fueled with second-generation Bio-fuel and development of ANN based prediction model. Applied Energy 187: 84-95. 